Rev. Interd. em Cult. e Soc. (RICS), São Luís, v. 6, n. 1, p. 187- 197, jan./jun. 2020

ISSN eletrônico: 2447-6498

\title{
Discursos sobre a Tortura de Mulheres Grávidas durante a Ditadura Militar ${ }^{1}$
}

\author{
Discourses on the Torture of Pregnant Women During Military \\ Dictatorship
}

\author{
JOSÉ VERANILDO LOPES DA COSTA JÚNIOR \\ Doutor em Letras e Professor Adjunto do Departamento de Letras Estrangeiras da \\ Universidade do Estado do Rio Grande do Norte - Campus Avançado de Pau dos Ferros. \\ jveranildo@hotmail.com
}

\section{RESUMO}

Em diversas fontes, tais como a história, a literatura e as artes, a ditadura foi denunciada por atentar contra os direitos humanos, através de práticas de violência em desacordo com a dignidade humana. Muitos foram os instrumentos de tortura, como o choque elétrico, o 'pau de arara' e o afogamento. Neste texto, além de discorrer sobre as práticas de tortura direcionadas aos sujeitos que se opuseram ao regime militar, analisaremos os depoimentos de três mulheres grávidas: Maria Barros dos Santos, Márcia Bassetto Paes e Helena Pignatari, disponíveis para acesso público no relatório da Comissão Nacional da Verdade (2014), sob a ótica da representação discursiva, de Adam (2011), vinculada à Análise Textual do Discurso. As análises apontam para a construção de narrativas que, ao falar de si, relatam uma série de violências cometidas pelos militares, causando traumas e provocando o aborto dessas mulheres.

Palavras-chave: Ditadura. Tortura. Mulher e gênero. Gravidez.

\begin{abstract}
In various sources, such as history, literature and the arts, the dictatorship was denounced for violating human rights, through practices of violence at odds with human dignity. There were many instruments of torture, such as the electric shock, the 'macaw stick' and drowning. In this text, in addition to discussing the torture that was practiced directed at subjects who opposed the military regime, we will analyze the testimonies of three pregnant women: Maria Barros dos Santos, Márcia Bassetto Paes and Helena Pignatari, available for public access in the report of the National Commission of the truth (2014), from the perspective of discursive representation, by Adam (2011), linked to Textual Discourse Analysis. The analyzes point to the construction of narratives that, when talking about themselves, report a series of violence committed by the military, due to the fact that they caused trauma and the abortion of these women.
\end{abstract}

Keywords: Dictatorship. Torture. Women and gender. Pregnancy.

\section{INTRODUÇÃO}

Gostaríamos de iniciar o conjunto de reflexões as quais propomos desenvolver ao longo deste texto com um excerto de um discurso proferido pela escritora africana Chimamanda Adichie, em 2009: "Quando nós rejeitamos uma única história, quando percebemos que nunca há apenas uma história sobre nenhum lugar, nós reconquistamos um tipo de paraíso". É certo que a referida escritora não vivenciou e pode, inclusive, desconhecer as narrativas construídas em torno do período ditatorial no Brasil. Contudo, interessa-nos a reflexão de Chimamanda que, em linhas gerais, pode ser compreendida da

\footnotetext{
${ }^{1}$ Artigo submetido para avaliação em 23/01/2019 e aprovado em 10/03/2020.
} 
Rev. Interd. em Cult. e Soc. (RICS), São Luís, v. 6, n. 1, p. 187- 197, jan./jun. 2020

ISSN eletrônico: $2447-6498$

seguinte forma: É necessário ir além do discurso oficial. É preciso desconfiar das histórias que nos contam. É fundamental conhecer o outro lado dessa história.

Nesse sentido, o presente texto é parte de um conjunto de reflexões ${ }^{2}$ que desenvolvemos sobre as representações (sempre no plural) da ditadura nas páginas da literatura e da história latino-americana. A partir do nosso interesse pessoal para com a temática do regime autoritário instaurado em diversos países da América Latina do século passado, buscamos interpretar a ditadura a partir dos estudos de gênero.

A leitura que propomos realizar nesse espaço não se debruça sobre textos literários, mas foca em relatos de mulheres que viveram o período de autoritarismo no Brasil. Em nosso país, a ditadura iniciou em 1964 e perdurou por vinte anos. Estudiosos afirmam que muitas foram as razões que possibilitaram a tomada do poder pelos militares como, por exemplo, o apoio da sociedade civil. Para Costa Junior (2020, p. 10):

\begin{abstract}
Diversas variantes facilitaram o golpe dos militares à democracia brasileira. Destaca-se, nesse contexto, a Marcha da Família com Deus e pela Liberdade, nome dado a uma série de manifestações ocorridas entre março e junho de 1964, que culminou na derrubada do então presidente João Goulart, popularmente conhecido por Jango, por setores ultraconservadores, formados pela Igreja, empresários e grupos políticos de direita.
\end{abstract}

Anos depois, em 2014, a Comissão Nacional da Verdade, importante entidade criada para investigar as violações dos direitos humanos ao longo da ditadura brasileira, apresentou um extenso e necessário relatório que sintetizou os mais diversos atentados contra a dignidade humana e ao Estado democrático quando se instaurou o período autoritário em nosso país (1964 - 1985). Esse relatório é composto por depoimentos de inúmeras pessoas que foram vítimas - direta ou indiretamente ${ }^{3}$ - desse movimento antidemocrático.

A partir dessa fonte histórica, propomos trazer para discussão os depoimentos de três mulheres que foram torturadas pelos militares: Rosa Maria Barros dos Santos, Márcia Bassetto Paes e Helena Pignatari Werner. A narrativa dessas mulheres grávidas mostra que é urgente interpretar a ditadura a partir dos estudos de gênero, para compreender que os grupos dissidentes - e nesse caso, as mulheres - além de terem sido torturadas por suas posições

\footnotetext{
${ }^{2}$ A tese de Doutorado intitula-se Homossexualidade e autoritarismo: uma leitura de Herbert Daniel, Osvaldo Bazán e Pedro Lemebel, desenvolvida junto ao Programa de Pós-Graduação em Letras da Universidade do Estado do Rio Grande do Norte. A pesquisa citada analisa personagens gays durante as ditaduras latinoamericanas.

3 Além de depoimentos das vítimas diretas da ditadura, o relatório também conta com depoimentos dos familiares das vítimas, e por isso, justifica-se o termo "vítimas indiretas da ditadura".
} 
Rev. Interd. em Cult. e Soc. (RICS), São Luís, v. 6, n. 1, p. 187- 197, jan./jun. 2020

ISSN eletrônico: $2447-6498$

ideológicas contrárias ao regime militar, também sofreram uma perseguição política motivada por questões de gênero e sexualidade, por exemplo.

Para além dessa discussão, o depoimento dessas mulheres ilustra a perversão do regime ditatorial, sendo necessário dizer que, no caso das mulheres grávidas, a tortura não se deu, exclusivamente, de forma física, mas a tortura psicológica foi uma ferramenta utilizada pelos militares como mecanismo para ocasionar o aborto e a interrupção de suas gestações.

Por fim, nosso texto também partilha da asserção de pesquisa elaborada pela professora Eurídice Figueiredo no seu estudo intitulado A literatura como arquivo da ditadura: "parto da premissa de que o golpe de 1964 foi um atentado à legalidade e à constituição, instaurando um regime de exceção, em que as liberdades eram tolhidas por um regime opressor" (FIGUEIREDO, 2017, p. 14). Por essa linha de pensamento, tratar do regime militar implica reconhecer nosso compromisso de memória com o passado e com todos aqueles que foram vítimas dos militares no Brasil.

\section{PROCEDIMENTOS METODOLÓGICOS}

De acordo com Prodanov e Freitas (2013), nosso artigo é uma pesquisa exploratória, uma vez que se debruça sob alguns depoimentos de vítimas da ditadura brasileira. É também de base documental, pois se ocupa de um relatório de acesso público elaborado pela Comissão Nacional da Verdade, em 2014.

Neste relatório, encontramos algumas narrativas de depoentes vítimas da ditadura brasileira. O documento é composto por cinco partes. Tomamos como corpus a terceira parte do relatório, intitulada "Métodos e práticas nas graves violações de direitos humanos e suas vítimas”. Os relatos discutidos estão, mais especificamente, dispostos ao longo do capítulo $\mathrm{X}$, "Violência sexual, violência de gênero e violência contra crianças e adolescentes".

Nesta análise discursiva, vinculada à representação discursiva, de Adam (2011), oriunda da Análise Textual do Discurso (ATT), é de nosso interesse perceber como mulheres grávidas perseguidas durante a ditadura brasileira relatam torturas sofridas que levam à interrupção da gravidez e, consequentemente, ao aborto.

\section{NARRAR PARA NÃO ESQUECER}

No Brasil, ainda são poucas as pesquisas que analisam o período ditatorial a partir dos marcadores dissidentes como, por exemplo, as questões de gênero e sexualidade. Nesse 
Rev. Interd. em Cult. e Soc. (RICS), São Luís, v. 6, n. 1, p. 187- 197, jan./jun. 2020

ISSN eletrônico: 2447-6498

sentido, o relatório elaborado pela Comissão Nacional da Verdade (2014) coloca em questão o tema das relações de gênero e de sexualidade durante o período ditatorial no Brasil. $\mathrm{O}$ documento citado, na III parte intitulada Métodos e práticas nas graves violações de direitos humanos e suas vítimas ${ }^{4}$ põe em pauta a discussão sobre gênero no Capítulo 10 Violência sexual, violência de gênero e violência contra crianças e adolescentes. Este capítulo divide-se em outros cinco tópicos, citados abaixo:

a) A violência sexual e de gênero como instrumento de poder e dominação;

b) Normativa internacional, violência sexual e violência de gênero;

c) A preponderância da violência sexual - métodos e procedimentos;

d) Consequências para os sobreviventes;

e) A violência contra crianças e adolescentes, o legado traumático e sua transmissão.

Dessa forma, o relatório da Comissão Nacional da Verdade encontra-se em consonância com o 'dever de memória', proposto pelo filósofo francês Paul Ricouer, o qual pode ser sintetizado com as seguintes palavras: é "[...] o dever de fazer justiça, pela lembrança, a um outro que não a si” (RICOUER, 2007, p. 101). Partindo desse compromisso com o passado, este documento apresenta uma série de narrativas de vítimas da ditadura no Brasil. Ao buscar uma aproximação com a questão de gênero discutida no relatório da Comissão Nacional da Verdade (2014, p. 400), recorremos à apresentação do Capítulo 10:

\begin{abstract}
A violência sexual, exercida ou permitida por agentes de Estado, constitui tortura. Por transgredir preceitos inerentes à condição humana ao afrontar a noção de que todas as pessoas nascem livres e iguais em dignidade e direitos, a normativa e a jurisprudência internacionais consideram que a violência sexual representa grave violação de direitos humanos e integra a categoria de "crimes contra a humanidade". No cumprimento de seu mandato, ao buscar promover o esclarecimento circunstanciado de casos de tortura ocorridos durante a ditadura militar, a Comissão Nacional da Verdade (CNV) pôde constatar que a violência sexual constituiu prática disseminada do período, com registros que coincidem com as primeiras prisões, logo após o golpe de Estado. Assim, este capítulo é dedicado à violência estruturada pela hierarquia de gênero e sexualidade, que busca anular a dignidade dos indivíduos violados, impedindo-os de viver como querem, de viver bem e sem humilhações. Tal violência atinge de forma diversa mulheres e homens, como mostram as investigações e os testemunhos realizados pelo grupo de trabalho "Ditadura e Gênero".
\end{abstract}

O que se pode notar, a partir dessas informações, é a recorrência de um mecanismo de institucionalização da violência durante a ditadura por parte dos militares. Porém, no senso comum, transita uma representação discursiva que tenta promover um

\footnotetext{
${ }^{4}$ Disponível em: http://cnv.memoriasreveladas.gov.br/ Acesso em 10 de janeiro de 2018.
} 
Rev. Interd. em Cult. e Soc. (RICS), São Luís, v. 6, n. 1, p. 187- 197, jan./jun. 2020

ISSN eletrônico: $2447-6498$

revisionismo da história ao afirmar que, durante a ditadura, não havia violência, ou que as pessoas viviam em paz, sob o controle dos militares. Contudo, pesquisas em diversas fontes do saber nos mostram que havia, neste período, uma institucionalização da violência, como discutido em nossa tese de Doutorado (COSTA JUNIOR, 2020), por exemplo.

Outros importantes estudos produzidos no Brasil corroboram a denúncia aos crimes cometidos pelos militares, e aqui recomendamos o importante documento escrito pela Arquidiocese de São Paulo, intitulado Brasil nunca mais (2011), com prefácio de Dom Paulo Evaristo Arns. Nesse texto, a Igreja católica sintetiza, pelo menos, nove práticas ${ }^{5}$ de torturas e de violência institucionalizada pelo Estado, a saber:

1- O pau de arara: "consiste numa barra de ferro que é atravessada entre os punhos amarrados e a dobra do joelho, sendo o "conjunto" colocado entre duas mesas, ficando o corpo do torturado pendurado a cerca de 20 ou $30 \mathrm{~cm}$ do solo. Este método quase nunca é utilizado isoladamente, seus "complementos" normais são entrechoques, a palmatória, o afogamento" (ARQUIDIOCESE DE SÃO PAULO, 2014, p. 35).

2- O choque elétrico: "o eletrochoque é dado por um telefone de campanha do Exército que possuía dois fios longos que são ligados ao corpo, normalmente nas partes sexuais, além dos ouvidos, dentes, língua e dedos" (ARQUIDIOCESE DE SÃO PAULO, 2014, p. 36).

3- A "pimentinha" e dobradores de tensão: "um magneto cuja característica era produzir eletricidade e alta amperagem: que, essa máquina por estar condicionada em uma caixa vermelha recebia a denominação de "pimentinha"” (ARQUIDIOCESE DE SÃO PAULO, 2014, p. 36)

4- O "afogamento": "o afogamento é um dos "complementos" do pau de arara. Um pequeno tubo de borracha é introduzido na boca do torturado e passa a lançar água" (ARQUIDIOCESE DE SÃO PAULO, 2014, p. 37).

5- A cadeira do dragão, de São Paulo: "também recebeu choques elétricos, cadeira do "dragão", que é uma cadeira elétrica de alumínio, tudo isso visando obtenção de suas declarações” (ARQUIDIOCESE DE SÃO PAULO, 2014, p. 38).

6- A cadeira do dragão, do Rio: "Uma cadeira de madeira pesada com braços cobertos de zinco ou flandres, onde havia uma travessa que era utilizada para empurrar para trás as pernas dos torturados” (ARQUIDIOCESE DE SÃO PAULO, 2014, p. 38).

7- A geladeira: Que por cinco dias foi metida numa "geladeira" na Polícia do Exército, na Barão de Mesquita” (ARQUIDIOCESE DE SÃO PAULO, 2014, p. 38).

8- Insetos e animais: "a interrogada quer ainda declarar que durante a primeira fase do interrogatório foram colocadas baratas sobre o seu corpo, e introduzida uma no seu ânus" (ARQUIDIOCESE DE SÃO PAULO, 2014, p. 40);

9- Produtos químicos: "torturas constantes de choques elétricos em várias partes do corpo, inclusive nos órgãos genitais e injeção de éter, inclusive com borrifos nos olhos” (ARQUIDIOCESE DE SÃO PAULO, 2014, p. 41).

\footnotetext{
${ }^{5}$ Estas práticas de tortura são conceituadas a partir de depoimentos dos torturados.
} 
Rev. Interd. em Cult. e Soc. (RICS), São Luís, v. 6, n. 1, p. 187- 197, jan./jun. 2020

ISSN eletrônico: 2447-6498

Certamente, outros instrumentos de tortura foram utilizados pelos militares, como forma de agredir a dignidade humana e violentar aqueles que se colocavam contrários ao regime antidemocrático. Homens e mulheres foram torturados por esses perversos instrumentos de violação humana. No caso particular das mulheres, "uma eventual gravidez a torna especialmente vulnerável. Por serem do sexo masculino, os torturadores fizeram da sexualidade feminina objeto especial de suas taras" (ARQUIDIOCESE DE SÃO PAULO, 2014, p. 48).

Embora não houvesse diferença nos meios de tortura utilizados contra homens e mulheres, muitas destas mulheres grávidas, além de violentadas fisicamente, foram também torturadas psicologicamente. Quando presas, diversas mulheres sofreram abortos causados pelos instrumentos de tortura e, aqui, é necessário recordar que, se a gestação da mulher não fosse interrompida, após o nascimento, suas crianças ${ }^{6}$ também poderiam ser torturadas.

Muitas mulheres relataram a tortura sofrida durante a gravidez. Estes depoimentos estão disponíveis em diversos documentos, como o Relatório da Comissão Nacional da Verdade (2014), analisado em nosso artigo. Para citar alguns exemplos, trazemos o depoimento de Rosa Maria Barros dos Santos, que em janeiro de 1971 foi presa e levada para o DOPS, na cidade de Recife - Pernambuco:

Levaram a gente para aquela solitária, e aí eu comecei a sentir umas dores, umas
dores absurdas, absurdas. Como cólica menstrual, assim, absurdo, eu rolei no chão
mesmo de dor, rolava no chão, e começou um sangramento cheio de pedaços de
coisas, assim... Que eu achei estranho porque nunca menstruei desse jeito. Nunca
tive essas cólicas. Que diabo é isso? Rolava, chorava, gritava de dor. Até que
apareceu um cara para saber o que estava acontecendo. Eu falei que estava com
muita dor, cólica, não sabia o que estava acontecendo comigo, aí eles trouxeram dois
comprimidos de AAS, que é absolutamente contraindicado para uma pessoa que está
abortando. O AAS, ele é facilitador do aborto, entendeu? Aí, eu abortei
completamente mesmo. De qualquer forma, naquela situação foi uma sorte. Depois,
conversando com a minha ginecologista, ela falou: "Foi uma sorte, Rosa. Você fez
um aborto completo, porque se você tivesse feito um aborto incompleto,
provavelmente, você morreria" [...] Eu estava bem no comecinho da gestação [...]
não centrei nisso, de jeito nenhum. Nenhum momento fiquei, ah, eu abortei, ah,
perdi meu filho. Parece que eu tava assim, obnubilada (COMISSÂO NACIONAL
DA VERDADE, 2014, p. 412).

A narrativa de Rosa Maria Barros dos Santos exemplifica a perversidade dos militares que, quando perceberam que ela estava perdendo o seu bebê, medicaram-lhe com um remédio facilitador do aborto. Em muitos casos, os militares ironizavam dizendo que as

\footnotetext{
${ }^{6}$ Para mais informações, consultar o livro Infância roubada: crianças atingidas pela ditadura militar no Brasil, organizado pela Comissão da Verdade do Estado de São Paulo "Rubens Paiva" (2014). Link para acesso: https://www.al.sp.gov.br/repositorio/bibliotecaDigital/20800_arquivo.pdf
} 
Rev. Interd. em Cult. e Soc. (RICS), São Luís, v. 6, n. 1, p. 187- 197, jan./jun. 2020

ISSN eletrônico: 2447-6498

mulheres haviam sofrido um aborto "espontâneo", mas é evidente que essas interrupções da gravidez dessas mulheres eram resultado da violência e da tortura legitimada pelos militares brasileiros.

A seguir, apresentamos o depoimento de Márcia Basseto Paes, presa no DOPS da cidade de São Paulo:

Estava grávida, já entrando no quinto mês de gravidez. Só que as minhas forças físicas não faziam perceber e minha infanti..., ingenui..., imaturidade para a situação também não. Eu fui torturada grávida. [...] Essa situação, eu só consegui elaborar agora. Essa é a primeira vez que eu estou contando, abrindo, colocando isso. Porque nesse período, no final do ano de 1977, eu passei por vários processos depressivos [choro] [...] Essa questão da gravidez que eu tive, esse aborto, me deixou com um problema muito grande em relação à maternidade [...] Eu fiquei mais de uma vez grávida, em 1979. E perdi essa criança no oitavo mês. Eu matei essa criança, perdi essa criança no oitavo mês. Meu organismo não tinha condições de, de segurar uma gravidez. [...] A questão da maternidade para mim, eu "pacotei", "pacotei" e arquivei bem no fundo de algum lugar. E não quis mais ter filhos. Mas, já com 38 anos, alguma coisa, o relógio biológico bate na gente e eu quis ter filho. [...] fui procurar tratamento médico. Porque eu não conseguia engravidar. Eu engravidava, mas eu perdia. Isso faz 20 anos (COMISSÃO NACIONAL DA VERDADE, 2014, p. 412).

Em seu depoimento, Márcia relata que o causador da impossibilidade da gravidez em outros momentos de sua vida, como no oitavo mês, foi o trauma de um aborto sofrido durante o quinto mês da sua primeira de gestação, quando a depoente passou por uma sessão de tortura. Aqui, percebemos como um trauma vivido pode trazer ressonância para outros momentos da vida do torturado.

Posteriormente, apresentamos o depoimento de Helena Pignatari Werner, que estava grávida e foi presa em um quartel em Osasco, no Estado de São Paulo:

Eu comecei a pensar nos meus alunos, eu sabia que eu tinha muitos alunos
envolvidos em movimentos socialistas, sindicalistas. [...] tudo isso na minha cabeça
foi dando um pânico tão grande, um medo de falar o nome de um aluno, o medo foi
tão grande, foi uma coisa assim... tão inumana, que eu tenho a impressão que com
aquele pavor, aquela coisa toda, que eu só pensava nos alunos, que eles iam me
torturar, e que eu não ia falar o nome de nenhum aluno, eu não podia falar um nome,
eu não queria falar um nome, eu não ia falar um nome, essa coisa tão apavorante, e
eles sempre naquela mesma rotina "a senhora vai ser chamada", passava outra noite,
"a senhora vai ser chamada", olha, vai aumentando o pavor [...] foi aí que eu abortei
(COMISSÃO NACIONAL DA VERDADE, 2014, p. 413).

De acordo com a narrativa de Helena, a tortura psicológica sofrida por ela resultou na interrupção de sua gestação. Ela era professora e os militares diziam que a convocariam para depor sobre os possíveis nomes de alunos que faziam parte dos movimentos sindicalistas 
Rev. Interd. em Cult. e Soc. (RICS), São Luís, v. 6, n. 1, p. 187- 197, jan./jun. 2020

ISSN eletrônico: 2447-6498

e socialistas durante o período ditatorial. O sentimento de medo causou a interrupção da gestação de Helena.

Com esses depoimentos, ilustra-se uma política de tortura e de violência institucionalizada por parte dos militares contra as pessoas que criticavam o regime ditatorial brasileiro. Poderíamos dizer que os militares torturavam as mulheres grávidas como uma medida para satisfazer as suas perversões e, certamente, causar danos à mulher torturada, ao esposo (que muitas vezes assistia à tortura) e as suas respectivas famílias.

Sobre os depoimentos das três mulheres grávidas, voltamos ao complexo questionamento da psicanalista Maria Rita Kehl (2014, p. 15): “Quantos anos ou décadas, são necessários para que um fato traumático se incorpore à memória social sem machucar nem se banalizar?”. Nesse sentido, quando Márcia Basseto Paes (2014, p. 412), ao relatar: "Eu fui torturada grávida. [...] Essa situação, eu só consegui elaborar agora”, reforça que, no processo de narrativa do trauma, as violências sofridas são revividas e ressignificadas através da memória daqueles que relatam. Quando o torturado vence o trauma, o depoimento transforma-se em memória cultural, para utilizar os termos de Aleida Assmann (2011).

Os relatos das mulheres citadas nesse texto também exemplificam a força do feminino em situações insalubres, como no caso da professora Helena Pignatari que, mesmo grávida, não citou os nomes de seus alunos que militavam contra a ditadura. O que se percebe nos três depoimentos, além da violência institucionalizada contra as mulheres, é a resistência do feminino na luta contra o autoritarismo.

Por outro lado, a violência de gênero não se limitou às mulheres. No conhecido estudo Ditadura e homossexualidades: repressão, resistência e a busca da verdade (2014), os historiadores James N. Green e Renan Quinalha (org.), especialistas em ditadura brasileira, afirmam que:

Do cruzamento entre a ditadura e as homossexualidades, diversas questões emergem de plano. Quais foram os efeitos da ditadura no cotidiano de mulheres que amavam outras mulheres, de homens que desejavam outros corpos masculinos ou mulheres e homens que se recusaram a reproduzir as noções e os comportamentos hegemônicos de gênero? (GREEN, QUINALHA, 2014, p. 19)

Dado o referido contexto, esse período de autoritarismo, além de fascista, caracteriza-se pelo machismo, pela misoginia e pelo binarismo de gênero operante. Green e Quinalha (2014) também sustentam a ideia de que, embora o período ditatorial no Brasil se caracterize pelo intenso aparato de repressão às liberdades individuais, o que se percebe é um movimento de resistência dos grupos dissidentes. Com isto, o movimento feminista tem 
Rev. Interd. em Cult. e Soc. (RICS), São Luís, v. 6, n. 1, p. 187- 197, jan./jun. 2020

ISSN eletrônico: 2447-6498

grande importância no processo de redemocratização brasileira e ao enfrentamento ao autoritarismo. Vera Soares, em Muitas faces do feminismo no Brasil (2014), ao revisar a trajetória do movimento feminista no Brasil a partir da década dos anos 70, sustenta:

\begin{abstract}
A presença das mulheres na cena social brasileira nas últimas décadas tem sido inquestionável. Durante os 21 anos em que o Brasil esteve sob o regime militar, as mulheres estiveram à frente nos movimentos populares de oposição, criando suas formas próprias de organização, lutando por direitos sociais, justiça econômica e democratização (SOARES, 2014, p.34).
\end{abstract}

Em uma lógica machista, o lugar da mulher é no âmbito privado-doméstico. Apesar disso, as mulheres estiveram presentes na luta contra a ditadura, organizando-se politicamente para reivindicar direitos e denunciar atrocidades. Vera Soares sustenta a ideia de que: "Foi durante a ditadura militar [...] que o movimento feminista foi capaz de produzir uma série de argumentos iluminando as ligações da violência contra a pessoa e contra as mulheres na esfera doméstica" (SOARES, 2014, p. 35). Isto resultou em mais processo de rompimento da lógica patriarcal, pois ao se organizarem nos movimentos sociais, mostravam que o espaço público também poderia ser ocupado pelo feminino, em oposição ao processo de submissão masculina.

\title{
4 CONCLUSÕES
}

Nesse texto, lançamos algumas considerações sobre um tema complexo e que merece mais atenção nas pesquisas desenvolvidas acerca do período ditatorial brasileiro: a tortura sofrida por mulheres grávidas. A nossa contribuição em torno desta discussão ressalta, em primeiro lugar, a necessária leitura da ditadura a partir dos estudos de gênero. Pesquisar o período de autoritarismo vivido no Brasil significa considerar que parte das torturas e das violências aos grupos dissidentes se deu, também, por questões de gênero e de sexualidade.

Nessa linha de pensamento, os torturadores eram homens, militares, majoritariamente enviesados por um binarismo de gênero operante entre masculino e feminino. Para esse setor ultraconservador da esfera social, ou seja, os militares, a única resolução para a equação que envolve o binarismo entre homens e mulheres é a submissão do feminino ao masculino, caracterizando uma sociedade patriarcal marcada pela hegemonia masculina.

Ao longo do artigo, discorremos sobre algumas práticas de tortura aplicadas durante a ditadura militar. Com isto, mostramos que as mulheres eram violentadas em duas 
Rev. Interd. em Cult. e Soc. (RICS), São Luís, v. 6, n. 1, p. 187- 197, jan./jun. 2020

ISSN eletrônico: 2447-6498

esferas: no campo físico e no contexto psicológico. As violências institucionalizadas resultaram na interrupção da gravidez de muitas mulheres, formando memórias traumáticas acerca da gestação.

Evidenciamos também a importância da pesquisa desenvolvida em torno da temática da ditadura militar no Brasil como mecanismo de justiça e memória. É essencial recordar que, por muito tempo, o Brasil não revisitou o passado e as memórias sobre a ditadura. Para citar um exemplo, São Paulo ainda tem 39 nomes de ruas com nomes de torturadores da ditadura ${ }^{7}$, o que mostra que ainda precisamos realizar um árduo trabalho de justiça e de memória sobre o período histórico em questão.

Revisitar o passado e punir os torturadores é fundamental para garantir um Estado brasileiro de direito, de justiça e de memória. Outrossim, também é necessário rechaçar e punir discursos revisionistas da história, como o do presidente Jair Bolsonaro que em 2019 determinou a comemoração do golpe de 1964 no interior dos quartéis brasileiros. Para concluir a nossa discussão, citamos as palavras da presidenta Dilma Rousseff, em 2014, na ocasião de entrega do relatório final da CNV: "A verdade liberta daquilo que permanece oculto" $"$.

\section{REFERÊNCIAS}

ADAM, J-M. A linguística textual: introdução à análise textual dos discursos. Tradução de Maria das Graças Soares Rodrigues, João Gomes Silva Neto, Luis Passegi e Eulália Vera Lúcia Fraga Leurquin. São Paulo: Cortez, 2011.

ASSMANN, A. Espaços da recordação: formas e transformações da memória cultural. Tradução de Paulo Soethe. Campinas, SP: Editora da Unicamp, 2011.

ARQUIDIOCESE DE SÃO PAULO. Brasil nunca mais. Petrópolis, RJ: Vozes, 2011.

CHIMAMANDA, A. N. O perigo de uma única história, 2009. Disponível em: https://papodehomem.com.br/o-perigo-de-uma-unica-historia/ Acesso em: 05 de janeiro de 2018.

COSTA JUNIOR, J. V. L. da. Homossexualidade e autoritarismo: uma leitura de Herbert Daniel, Osvaldo Bazán e Pedro Lemebel (Tese de Doutorado em Letras). Universidade do Estado do Rio Grande do Norte, Pau dos Ferros, 2020.

\footnotetext{
${ }^{7}$ Fonte: http:/a/www.redebrasilatual.com.br/cidadania/2017/04/ruas-da-vergonha-sao-paulo-ainda-tem-39-ruascom-nomes-de-torturadores Acesso em 10 de janeiro de 2018.

${ }^{8}$ Fonte: http://pensata.ig.com.br/index.php/2014/12/13/depoimento-de-dilma-sobre-tortura-em-relatorio-da-cnvopoe-presidente-e-forcas-armadas/ Acesso em: 11 de janeiro de 2018.
} 
Rev. Interd. em Cult. e Soc. (RICS), São Luís, v. 6, n. 1, p. 187- 197, jan./jun. 2020 ISSN eletrônico: 2447-6498

RELATÓRIO DA COMISSÃO NACIONAL DA VERDADE, 2014. Disponível em: http://cnv.memoriasreveladas.gov.br/ Acesso em: 10 de janeiro de 2018.

FIGUEIREDO, E. A literatura como arquivo da ditadura brasileira. Rio de Janeiro: 7Letras, 2017.

GREEN, J. N; QUINALHA, R (orgs). Ditaduras e homossexualidades: repressão, resistência e a busca da verdade. São Carlos, SP: EdUFSCAR, 2014.

KEHL, M. R. A ironia e a dor. In: KUCINSKI, B. Você vai voltar para mim e outros contos. São Paulo, SP: Cosac Naify, 2014.

PRODANOV, C. C; FREITAS, E. C. Metodologia do trabalho científico: métodos e técnicas de pesquisa e do trabalho acadêmico. Novo Hamburgo: Freevale, 2013.

SÃO PAULO (Estado). Assembleia Legislativa. Comissão da Verdade do Estado de São Paulo "Rubens Paiva". Infância roubada: crianças atingidas pela Ditadura Militar no Brasil. São Paulo: ALESP, 2014.

SOARES, V. Muitas faces do feminismo no Brasil. 2014. Disponível em: https://cbd0282.files.wordpress.com/2014/05/feminismonobrasil.pdf Acesso em: 11 de janeiro de 2018.

RICOUER, P. A memória, a história e o esquecimento. Tradução de Alain François. Campinas, SP: Editora Unicamp, 2007. 